\title{
Autophagy regulation and its dual role in blood cancers: A novel target for therapeutic development (Review)
}

\author{
SHENHE JIN ${ }^{1,3^{*}}$, JUYING WEI ${ }^{1,3^{*}}$, LIANGSHUN YOU ${ }^{1-3}$, HUI LIU $^{1,3}$ and WENBIN QIAN ${ }^{1-3}$ \\ ${ }^{1}$ Department of Hematology, The First Affiliated Hospital, College of Medicine; ${ }^{2}$ Institute of Hematology; \\ ${ }^{3}$ Malignant Lymphoma Diagnosis and Therapy Center, The First Affiliated Hospital, College of Medicine, \\ Zhejiang University, Hangzhou, Zhejiang 310003, P.R. China
}

Received September 4, 2017; Accepted April 4, 2018

DOI: $10.3892 / o r .2018 .6370$

\begin{abstract}
Autophagy, a physiological process in which cellular components are degraded by the lysosome for cell homeostasis, plays an important role in cell metabolism, including cell proliferation, differentiation, survival and apoptosis. Recent studies indicate that autophagy serves as a survival mechanism by eliminating misfolded proteins and attenuating DNA damage. Autophagy can also suppress tumor growth, depending upon the cell context and functional status. Dysfunction of autophagy may be closely linked to the initiation and development of various diseases, including hematological malignancies. Mounting evidence highlights the
\end{abstract}

Correspondence to: Professor Wenbin Qian, Institute of Hematology, Malignant Lymphoma Diagnosis and Therapy Center, The First Affiliated Hospital, College of Medicine, Zhejiang University, 79 Qingchun Road, Hangzhou, Zhejiang 31000, P.R. China E-mail: qianwb@zju.edu.cn

${ }^{*}$ Contributed equally

Abbreviations: ATG, autophagy-related genes; AMPK, AMP-activated protein kinase; ATRA, all-trans retinoic acid; $\mathrm{As}_{2} \mathrm{O}_{3}$, arsenic trioxide; ACD, autophagic cell death; ALL, acute lymphocytic leukemia; APL, acute promyelocytic leukemia; CQ, chloroquine; CML, chronic myeloid leukemia; CLL, chronic lymphocytic leukemia; CMA, chaperone-mediated autophagy; DAPK, death-associated protein kinase; DRAM-1, damage-regulated autophagy modulator 1; Dex; dexamethasone; DNR, daunorubicin; ER, endoplasmic reticulum; Fd, fludarabine; GABARAP, $\gamma$-aminobutyric acid receptorassociated proteins; HCQ, hydroxychloroquine; HSC, hematopoietic stem cell; HSP, heat shock protein; IM, imatinib; LC3, microtubuleassociated protein 1 light-chain 3; 3-MA, 3-methyladenine; MM, multiple myeloma; MDS, myelodysplastic syndrome; mTOR, mammalian target of rapamycin; PI3P, phosphatidylinositol 3-phosphate; PIP3, phosphatidylinositol (3,4,5)-trisphosphate; PE, phosphatidylethanolamine; PI3K, phosphatidylinositol 3-kinase; PML, primary effusion lymphoma; ROS, reactive oxygen species; TKI, tyrosine kinase inhibitor; ULK, unc-51-like kinase

Key words: autophagy, blood cancer, treatment dual role of autophagy in blood cancers through multifarious signal pathways. Therefore, strategies targeting autophagy will develop innovative therapeutic approaches for blood cancers, improve the efficacy of chemotherapy, and bring significant benefits for patients.

\section{Contents}

1. Introduction

2. Autophagy signal pathways in cancer

3. Autophagy in hematological malignancies

4. Conclusions and perspectives

\section{Introduction}

Autophagy is an evolutionarily conserved degradation process that plays an important role in maintaining cellular homoeostasis and metabolism. Unlike the proteasome system, autophagy mainly disintegrates long-lived proteins and impaired organelles, which are engulfed by autophagosomes and transported to lysosomes for the digestion when it is induced under stress conditions such as mitochondrial depolarization, nutrient starvation, aggregation of toxic proteins, and pathogen infection $(1,2)$. It is well known that there are three main types of autophagy: Macroautophagy (hereafter referred to as autophagy), microautophagy and chaperone-mediated autophagy (CMA). Microautophagy directly degrades cellular bulks via endocytic membrane emboly, whereas CMA only delivers specifically marked proteins to the lysosome. Macroautophagy involves the sequestration of cytosol or cytoplasmic organelles by the formation of autophagosomes that subsequently fuse with endosomes and eventually with lysosomes, thereby creating autophagolysosomes or autolysosomes, in which the cell contents are degraded $(3,4)$.

Autophagy is a multi-step process involving at least four distinct phases: i) Initiation and nucleation: the activation of autophagy is associated with the unc-51-like kinase (ULK) complex and phosphatidylinositol 3-kinase (PI3K) complex. Under stressful conditions such as hypoxia and starvation, mTOR complex 1 (mTORC1) is separated from the ULK complex, subsequently activating ULK $1 / 2$ and phosphorylating ATG13, ATG101 and FIP200 to induce phagophore formation. 
Simultaneously, the excitation of Beclin-1-VPS34-ATG14L generates phosphatidylinositol 3-phosphate (PI3P), motivating membrane proteins and phospholipids for phagophore nucleation (5-7). ii) Membrane elongation and completion: this process is mainly regulated via two ubiquitin-like conjugation complexes. On the one hand, combining with ATG4, LC3 (microtubule associated protein 1 light-chain 3) proteins split into LC3-I, which are incorporated with phosphatidylethanolamine (PE) with the help of ATG3 and ATG17, for the transformation of LC3-II, which surrounds both the internal and external membranes of the phagosome. In addition, the ATG12-ATG5 dipolymer conjugates with ATG16L to form the ATG12-ATG5-ATG16L complex, which can promote LC3 transformation and accelerate transformation from phagophore to autophagosome (8-12). iii) Maturation: the upregulation of $\gamma$-aminobutyric acid receptor-associated proteins (GABARAP) contributes to phagophore closure and the formation of airtight double-membrane autophagosomes (13). Rab7, LAMP1/2 proteins, ESCRT, UVRAG and SNAREs also participate in this procedure $(1,14,15)$. iv) Degradation: the outer membrane of the autophagosome fuses with the lysosome to create an autolysosome, whereas the inner membrane and engulfed components are degraded into small molecular nutrients (Fig. 1).

Mounting evidence has certified that autophagy affects cell metabolism, including cell proliferation, differentiation, survival and apoptosis (16). Autophagy facilitates clearance of damaged cytoplasmic components and maintains cell homeostasis when cells are submitted to hostile environments. Nevertheless, immoderate autophagy can induce autophagic cell death (ACD), also known as type II programmed cell death, leading to tumor self-degradation (17-20). In addition, excessive autophagy can deplete mitochondria and metabolic substances, thereby trapping cells in the state of hunger $(21,22)$. Autophagy can also mobilize cell survival substances to autophagosomes for degradation, incurring the accumulation of reactive oxygen species (ROS), caspases, and concomitant cell death $(23,24)$. This evidence may also explain the antitumor mechanisms of autophagy. Notably, in blood tumors, the role of autophagy remains elusive. In this review, we discuss the autophagy molecular mechanism, its relative signal pathways, and focus on its dual role in hematological malignancies, which may provide some novel strategies for treatment of hematological tumors.

\section{Autophagy signal pathways in cancer}

The autophagy signal pathways are intricate networks. In this section, we introduce the main molecular regulators of autophagy. A deeper understanding of these regulatory pathways may provide us with potential targets against tumorigenesis (Fig. 2).

Phosphatidylinositol 3-kinase (PI3K) signaling. The phosphatidylinositol 3-kinases are a family of enzymes that can phosphorylate phosphoinositides of cell membranes, and have thus been deemed as the initiators of cellular signal transduction. PI3Ks are divided into three classes. However, only Class I and III PI3Ks have been shown to be associated with autophagy (25). The Class I PI3K promotes the generation of phosphatidylinositol-3,4,5-trisphosphate (PIP3) at the plasma membrane, thereby increasing Akt/PKB recruitment. The activated Akt/PKB hinders its downstream TSC1-TSC2 complex, influences GTP binding, and motivates the mammalian target of rapamycin (mTOR), which acts as a negative regulator of autophagy by sensing variable ATPs, amino acids, and energy metabolism $(2,26)$. In addition, mTOR can be directly inhibited by rapamycin treatment, leading to autophagy induction. Conversely, Class III PI3K activates autophagy. It phosphorylates PI to generate PI3P, which contributes to the movement of lysosomal enzymes for component degradation (27). Previous findings have shown that the Class III PI3K integral protein Beclin-1, which is also known as the mammalian homolog of an essential yeast autophagy gene (Atg6), can facilitate phagosome nucleation, maturation and clearance of apoptotic cells (28). Therefore, knockdown or silence of Beclin-1 inhibits autophagy and causes cell death (29).

$E R$ stress response. The endoplasmic reticulum (ER) is in charge of protein folding. Under stressed circumstances, the accumulation of immature proteins provokes ER stress response and boosts autophagy, resulting in autophagic cell death (30). This process is mainly regulated via the IRE1 $\alpha$-JNK and PERK-eIF2 $\alpha$-ATF4 pathways $(31,32)$.

AMP-activatedprotein kinase (AMPK) pathway.AMP-activated protein kinase is the energy sensor. In energy-defective situations (decreased ATP/AMP ratio and starvation), the AMPK is excited by LKB1 and p53, leading to autophagy activation via the positive regulation of the TSC1-TSC2 complex or negative regulation of mTOR. AMPK can also directly suppress the raptor, which is a subunit of mTORC1 that inhibits autophagy activity $(16,33)$.

RAS system. The relationship between RAS and autophagy is multifaceted. In fact, RAS plays both positive and negative roles in autophagy with different pathways. On the one hand, RAS inhibits autophagy by directly activating Class I PI3K-Akt-mTOR1. By contrast, RAS upregulates Raf-1/MEK/ERK- or Rac1/MKK7/JNK-dependent autophagy activity with the help of ATG5/7 and Beclin-1 (34-36).

The Bcl-2 family. The Bcl-2 family is divided into three types, based on their BH domains and functions. Bcl-2, $\mathrm{Bcl}-\mathrm{xL}$ and myeloid cell leukemia sequence-1 (MCL-1) act as anti-apoptosis pathways, while BAX-like proteins (BAX, BAK) and BH3-only proteins (BNIP3) promote apoptosis (2). Similarly, these proteins play a bidirectional role in autophagy. On the one hand, the BNIP3 can integrate with $\mathrm{Bcl}-2$, which correspondingly decreases $\mathrm{Bcl}-2$ binding to Beclin-1, thereby liberating Beclin-1 for autophagy induction $(37,38)$. By contrast, Bcl-2, Bcl-xL and MCL-1 inhibit autophagy.

Other autophagy networks. Death-associated protein kinase (DAPK) is associated with autophagy in cancer. Hyperactive DAPK influences its related protein kinase DRP-1, which increases plasma membrane flexing and blebbing, enabling phagocytosis (39). In addition to the aforementioned p53-AMPK network, DNA damage can trigger autophagy 


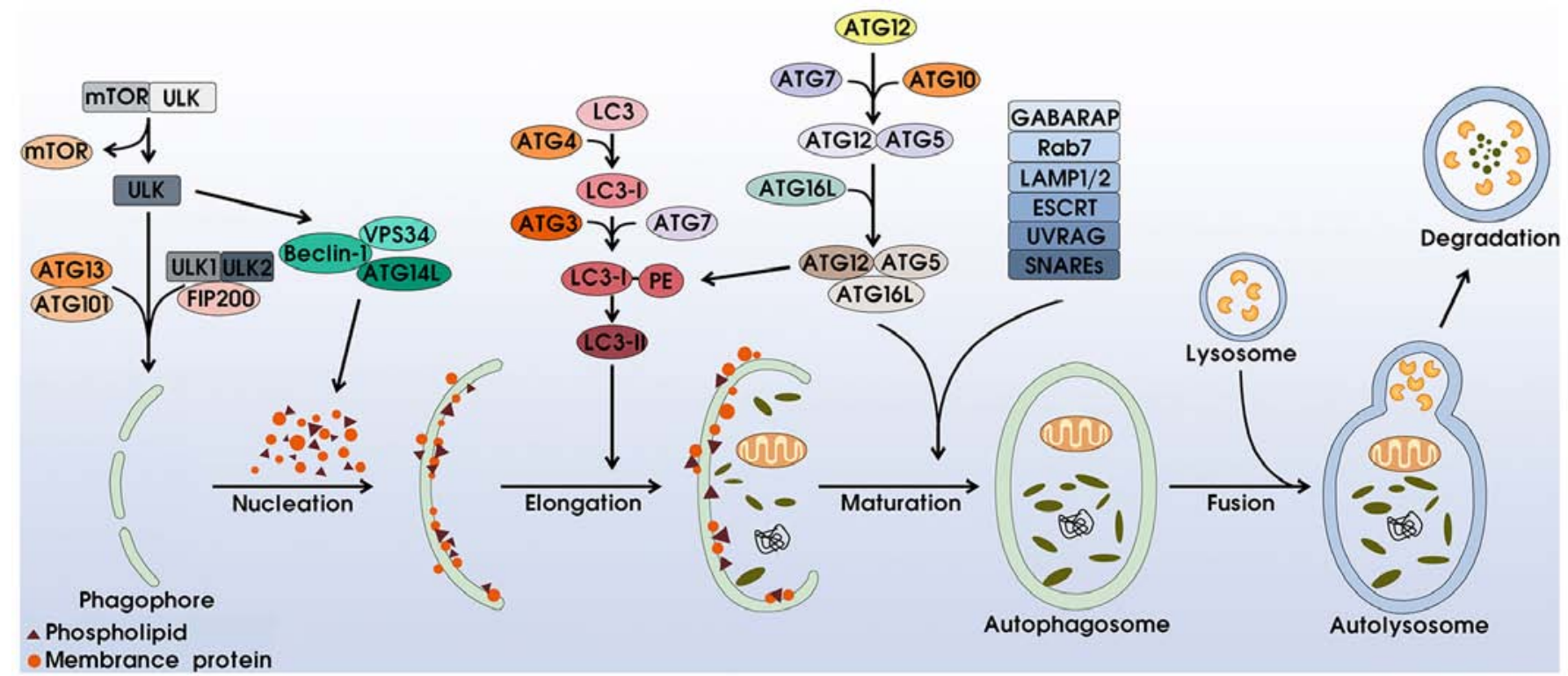

Figure 1. Schematic overview of the autophagy process. Autophagy is initiated from the inhibition of mTOR through starvation or other stressful conditions, followed by phagophore formation and nucleation, membrane elongation and completion, autophagosome maturation, and final degradation of engulfed components with the assistance of over 30 autophagy-related gene (ATG) proteins and two ubiquitin-like conjugation complexes, the ATG12-ATG5-ATG16 and the LC3-PE conjugation complexes.

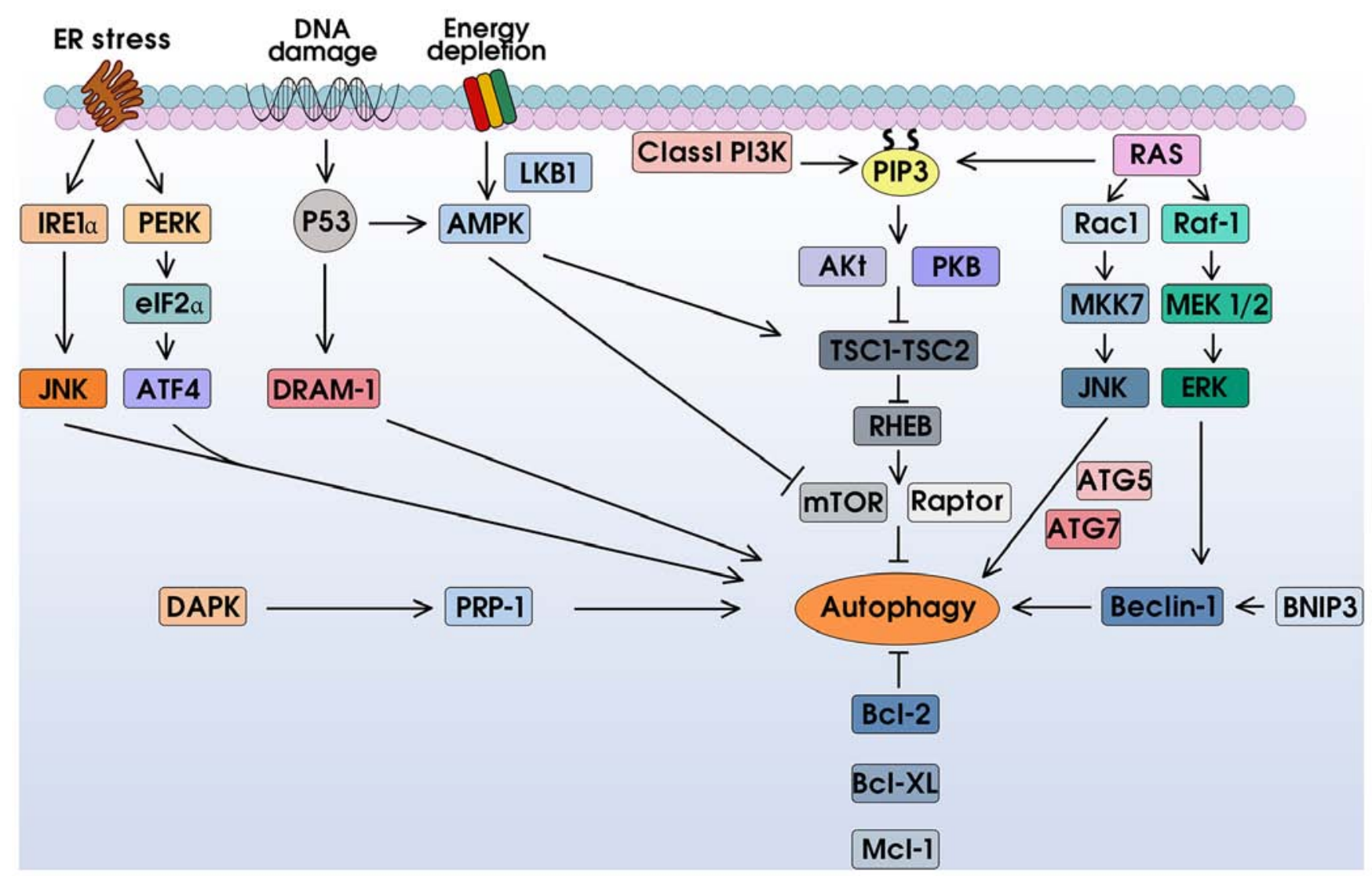

Figure 2. Schematic overview of signal regulations of autophagy in cancer. Autophagy is tightly controlled by several signaling pathways. The PI3K-AKTmTOR pathway plays the central role. The ER stress response regulates autophagy through the IRE1 $\alpha$-JNK and PERK-eIF2 $\alpha$-ATF4 pathways. The DNA damage and energy depletion can trigger autophagy by AMPK and p53 pathways. The RAS system inhibits or induces autophagy via the PI3K-AKT-mTOR or the Raf-1/MEK/ERK and Rac1/MKK7/JNK pathways, respectively. The Bcl-2 family also plays both positive and negative roles in autophagy regulation. Other pathways such as the DAPK-DRP1 signaling pathway are also important in regulating autophagy.

through p53-dependent damage-regulated autophagy modulator-1 (DRAM-1) activation (40).
In summary, autophagy networks are sophisticated. Dysfunctions of these signal pathways are involved in 
tumorigenesis, and targeting signal transduction proteins may provide potential therapeutic schemes for cancer.

\section{Autophagy in hematological malignancies}

Several studies have demonstrated the important role of autophagy in blood tumors. Autophagy participates in the regulation of hematopoietic stem cell (HSC) differentiation, and the downregulation of autophagy would facilitate leukemic transformation from normal HSC (41). Recently, the potential anti-leukemic effect of tetrandrine was proven through the promotion of the autophagy-dependent megakaryocytic differentiation of leukemia cells (42). In addition, Schläfli et al revealed that autophagy scaffold protein ALFY was, not only involved in APL cell differentiation induced by ATRA, but also contributed to degradation of oncoprotein PML-RAR $\alpha$ (43). However, autophagy also played a cytoprotective role and led to chemoresistance in leukemia. In lymphoma, on the one hand, autophagy was capable of suppressing lymphomagenesis through the modulation of autophagy proteins and signal pathways. On the other hand, activated autophagy acted as the mechanism of lymphoma cell survival, and additional autophagy inhibitors enhanced antitumor activity (44). The survival of myeloma cells was also dependent on autophagy for protein degradation and energy recycling, which potentially results in drug resistance. For example, Zhang et al reported that bortezomib induced pro-survival autophagy, which reduced the chemosensitivity of bortezomib in myeloma cells (45), whereas excessive autophagy may lead to autophagic cell death, providing an available approach for myeloma treatment (46). Therefore, we discussed the dual role of autophagy mediated by conventional chemotherapeutics and summarized promising strategies associated with autophagy modulation in Table I.

Autophagy as a pro-death mechanism. The pro-death role of autophagy is vital for suppressing tumor progression and enhancing antitumor response. Fludarabine ( $\mathrm{Fd})$, a nucleoside analog that inhibits DNA/RNA synthesis and DNA repair, is widely used for chronic lymphocytic leukemia (CLL). Mahoney et al observed fludarabine-triggered autophagy activity in CLL cells. However, the inhibition of autophagy did not enhance or diminish cell death induced by fludarabine (47). Recently, a study by Sharma et al reported that fludarabine induced BECN-dependent autophagy by decreasing Mcl-1 expression, resulting in autophagic cell death in Fd-sensitive leukemic B cells (48). However, in Fd-resistant leukemic cells, Mcl-1 expression was increased, which inhibited BECN-dependent autophagic cell death. The Bcl-2 family also contributed to promoting cell survival via sequestering BECN. Moreover, activated AMPK-dependent autophagy assisted Fd-resistant cells escape cell death. Of note, adding the BCL-2 inhibitor obatoclax can induce cell death in both Fd-sensitive and Fd-resistant leukemic cells. The findings suggest that combining autophagy repressors such as Mcl-1, Bcl-2 and AMPK inhibitors, with fludarabine may improve the curative effect for CLL patients, especially those who acquire Fd-resistance after several cycles of fludarabine chemotherapy.

Metformin, an anti-diabetic agent, has already been proven to play a positive role in cancer control, including acute leukemia (47-50). Wang et al reported that metformin enhanced the anti-leukemic effect of sorafenib by triggering mTOR-dependent autophagy in FLT3-ITD-positive AML, which suggested the combination strategy of the two drugs in AML treatment (51). Metformin also induced a dose-dependent inhibition of lymphoma cell proliferation in vitro and in vivo via the negative control of the mTOR signal pathway (52). Metformin-induced autophagy enhanced the anti-lymphoma effect of doxorubicin and temsirolimus (mTOR inhibitor), offering a novel therapeutic strategy.

Sertraline, a widely used antidepressant drug, was found to induce leukemia cell death mediated by autophagy and apoptosis. It also enhanced the sensitivity of chemotherapy drugs, thereby providing potential alternative strategies for leukemia treatment (53).

Trocoli et al observed that all-trans retinoic acid (ATRA) can promote autophagy by reducing the activity of Bcl-2 and mTOR in acute promyelocytic leukemia (APL). In addition, the upregulation of Beclin-1 contributed to the stability of mature APL cells in a non-autophagic manner, although autophagy-related cell differentiation was not explored (54). Notably, by combining ATRA with RAD001 (mTOR1C inhibitor), Nishioka et al observed step-down cell growth and enhanced cell differentiation of AML cells (55). Similarly, Isakson et al reported that ATRA-dependent autophagy induced the degradation of PML-RAR $\alpha$, which is known to create abnormal granulocytic differentiation, via inhibition of the mTOR pathway as well (56). Thus, the simultaneous use of ATRA and mTOR suppressant may be a valid protocol for APL patients.

Arsenic trioxide $\left(\mathrm{As}_{2} \mathrm{O}_{3}\right)$, another metalloid poison that has conventionally been used in APL patients, also induced cell death. We previously reported that $\mathrm{As}_{2} \mathrm{O}_{3}$ led to cell growth arrest by means of both apoptosis and Beclin-1-dependent autophagy (58). Goussetis et al also documented a MEK-ERK-mediated autophagic cell death in leukemia cells (59). The studies demonstrated $\mathrm{As}_{2} \mathrm{O}_{3}$-induced autophagy as the mechanism of cell death.

Autophagy in response to idarubicin served as a pro-death mechanism in leukemic cells as well. Idarubicin restrained mTOR either by upregulation of its upstream inhibitor AMPK, or downregulation of its activator Akt, thus leading to autophagic cell death. Pharmacological impairment (bafilomycin A1 or chloroquine) of autophagy partially reduced the cytotoxicity of idarubicin towards REH cells, which highlighted its cell-killing function (60).

Dexamethasone (Dex) also contributed to cell death in lymphoid leukemia and multiple myeloma. Several experiments observed Dex-induced autophagic cell death through the marked upregulation of promyelocytic leukemia protein (PML) and PML-dependent Akt dephosphorylation $(61,62)$. In depth studies on PML and Akt-dependent intracellular pathways may provide optimized use of Dex in the treatment of lymphoid malignancies.

Autophagy as a pro-survival mechanism. Besides its potential to induce cell death, autophagy is appropriated to serve as a cell survival mechanism as well.

For example, the tyrosine kinase inhibitor AG490 was found to induce both apoptosis and autophagy by inhibiting STAT3, reducing the expression of HSF1/HSP70, and 
Table I. Therapeutic compounds-induced autophagy and its outcomes in hematological malignancies.

\begin{tabular}{|c|c|c|c|c|c|}
\hline Compounds & Signal pathways & Types of tumor & Outcome & Additional treatment & Refs. \\
\hline Fludarabine & $\begin{array}{l}\text { Mcl-1-BECN1, } \\
\text { Bcl-2, AMPK }\end{array}$ & Leukemia & $\begin{array}{l}\text { Cell death/ } \\
\text { survival }\end{array}$ & Obatoclax & 48 \\
\hline Metformin & AMPK-mTOR & $\begin{array}{l}\text { B/T-lymphoma, } \\
\text { AML }\end{array}$ & Cell death & $\begin{array}{l}\text { Doxorubicin, temsirolimus, } \\
\text { sorafenib }\end{array}$ & $52-53$ \\
\hline Sertraline & Not mentioned & AML & Cell death & Not mentioned & 54 \\
\hline ATRA & Bcl-2, mTOR & APL & Cell death & Everolimus, rapamycin & $55-58$ \\
\hline $\mathrm{As}_{2} \mathrm{O}_{3}$ & $\begin{array}{l}\text { MEK-ERK, } \\
\text { Beclin-1 }\end{array}$ & Leukemia & Cell death & Not mentioned & $59-60$ \\
\hline Idarubicin & $\begin{array}{l}\text { AMPK-mTOR, } \\
\text { Akt-mTOR }\end{array}$ & Leukemia & Cell death & Not mentioned & 61 \\
\hline Dexamethasone & PML-Akt & $\begin{array}{l}\text { Leukemia, } \\
\text { multiple myeloma }\end{array}$ & Cell death & Rapalogues & $62-63$ \\
\hline 2-Deoxy-5-azacytidine & Intrinsic pathway & CML & Cell death & Not mentioned & 83 \\
\hline AG490 (TKI) & STAT3-Mcl-1 & PEL & Cell survival & $\begin{array}{l}\text { Bafilomycin, } \\
\text { 2-phenylethynesulfonamide }\end{array}$ & 64,66 \\
\hline Imatinib & $\begin{array}{l}\text { PI3K-AKT-mTOR, } \\
\text { Beclin-1 }\end{array}$ & CML & $\begin{array}{l}\text { Cell survival/ } \\
\text { death }\end{array}$ & 3-MA, CQ, NVP-BEZ235 & $67-72$ \\
\hline Interferon & $\begin{array}{l}\text { JAK1-STAT1, NF- } \mathrm{B}, \\
\text { BECN1 }\end{array}$ & CML & Cell survival & CQ & 73 \\
\hline Cytarabine & $\begin{array}{l}\text { Akt-mTOR, } \\
\text { AMPK, ERK }\end{array}$ & Leukemia & Cell survival & Bafilomycin, CQ & 74 \\
\hline $\begin{array}{l}\text { Doxorubicin, } \\
\text { Melphalan }\end{array}$ & $\begin{array}{l}\text { Bcl-2-Beclin-1, } \\
\text { Beclin-1-PI3KC3 }\end{array}$ & MM & Cell survival & HCQ, 3-MA & 75 \\
\hline Bortezomib & $\begin{array}{l}\text { JNK-Bcl2, } \\
\text { Bcl-2-Beclin-1, } \\
\text { Beclin-1-PI3KC3 }\end{array}$ & $\begin{array}{l}\text { B-ALL, } \\
\text { B-lymphoma }\end{array}$ & Cell survival & CQ, 3-MA, SP600125 & $76-77$ \\
\hline Daunorubicin & MEK-ERK & Myeloid leukemia & Cell survival & U0126 & 78 \\
\hline Dasatinib & AMPK & $\begin{array}{l}\text { CLL, } \mathrm{Ph}^{+} \\
\text {leukemia }\end{array}$ & $\begin{array}{l}\text { Cell survival/ } \\
\text { death }\end{array}$ & Not mentioned & $79-80$ \\
\hline Sorafenib & mTOR & MM & Cell survival & 3-MA, CQ, ABT737 & 81 \\
\hline L-asparaginase & ROS-p53 & ALL & Cell survival & CQ & 82 \\
\hline 5-Azacitidine & Beclin-1 & MDS & Cell survival & CQ, leupeptin & 84 \\
\hline
\end{tabular}

APL, acute promyelocytic leukemia; ATRA, all-trans retinoic acid; $\mathrm{As}_{2} \mathrm{O}_{3}$, arsenic trioxide; B-ALL, B acute lymphocytic leukemia; CML, chronic myeloid leukemia; CLL, chronic lymphocytic leukemia; CQ, chloroquine; HCQ, hydroxychloroquine; MM, multiple myeloma; MDS, myelodysplastic syndrome; 3-MA, 3-methyladenine; PML, primary effusion lymphoma; TKI, tyrosine kinase inhibitor.

downregulating Mcl-1 in primary effusion lymphoma (PEL) cells. A combination of AG490 with autophagy inhibitor bafilomycin is believed to enhance the cytotoxic effect $(63,64)$. The HSP70 and its main transcription factor HSF1 have been reported as essential for PEL survival by affecting protein folding and cell stability, and HSP70 inhibition via 2-phenylethynesulfonamide could block the autophagic process and induce immunogenic cell death (65). Therefore, a combination of AG490 and HSP inhibitors may provide a potential treatment strategy. Another TKI, imatinib (IM), was also reported to activate a cytoprotective autophagy in chronic myeloid leukemia (CML) (66). Rothe et al identified that CML stem/progenitor cells obtained imatinib resistance due to its intensive pro-survival activities associated with elevated autophagy gene transcripts and proteins, especially ATG4B (67). Mancini et al describe a survival role of autophagy in imatinib-treated Bcr-Abl-positive cells, possibly connected with ER stress and following responses (68). The group of Howard Hughes Medical Institute suggested that imatinib-induced autophagy was associated with the Bcr-Abl/ PI3K/Akt/FOXO4/ATF5/mTOR pathways (69). Recently, the combination of NVP-BEZ235 (dual PI3K/mTOR inhibitor) and imatinib was reported to significantly inhibit CML cell growth and proliferation, as well as enhance sensitivity to imatinib 
in imatinib-resistant CML cells (70). Inversely, imatinibinduced autophagy also isolated the mosaic gene $B c r-A b l$ in autophagosomes through the regulation of Beclin-1, which prevented disease progression (71). Therefore, autophagy inhibition of the aforementioned specific autophagic pathways would enhance the treatment effect of imatinib in CML.

Zhu et al also reported a pro-survival role of autophagy in CML treated with interferon. Interferon-1 activated both JAK1-STAT1 and NF- $\kappa$ B pathways, leading to increasing BECN1-ATG5-ATG7, one of the major regulators of the classical autophagy pathway. Inhibiting autophagy by using chloroquine enhanced the cytotoxic effect of interferon-1 (72).

Cytarabine was reported to increase the phosphorylation of AMPK/ERK, inhibit Akt and attenuate mTOR activity, thereby inducing cytoprotective autophagy in leukemic cells. Pharmacological (bafilomycin A1 and chloroquine treatment) or genetic (siRNA downregulation of either LC3b or autophagic cargo receptor p62) impairment of autophagy markedly increased cell death by accumulating DNA fragmentation and mitochondrial damage as well as activating oxidative stress, thus providing the combination strategy of cytarabine and autophagy inhibitor in leukemia treatment (73).

Notably, doxorubicin and melphalan were shown to motivate autophagy in multiple myeloma (MM) cells, which provided an adaptive condition for evading DNA-damaging stimulus. The increasing Beclin-1-PI3KC3 complex and Bcl-2 disintegrated from Beclin-1, functioned as a cell survival mechanism in this process. Thus, the inhibition of autophagy with DNA-damaging agents likely augmented anti-myeloma activities without additional side effects (74). In cases of acute lymphocytic leukemia (ALL) treated with bortezomib, cytoprotective autophagy was also associated with the balance between the Bcl-2-Beclin-1 complex and the Beclin-1-PI3KC3 complex, as its downregulation by chloroquine potentiated anti-ALL activity (75). The aforementioned results indicated a pivotal role of Bcl-2-Beclin-1-PI3KC3 complexes in autophagy and provided a novel target to improve clinical efficacy. Another experiment provided evidence of autophagic cell proliferation in aggressive B-cell lymphoma managed with bortezomib. In that study, ER stress-associated IRE1-JNK was stimulated, followed by phosphorylated Bcl-2 and elevated LC3-II, which was widely used for autophagic flex surveillance. Certainly, the addition of JNK inhibitor SP600125 enhanced the antilymphoma effects of bortezomib (76).

Anthracycline daunorubicin (DNR) revealed potent leukemia killing activity by DNA damage. However, DNR-induced autophagy was inversely cytoprotective, and authors of that study identified the activation of MAPK (MEK-ERK) in DNR-treated myeloid leukemia cells (77). Obviously, adding MEK1/2 inhibitor U0126 to daunorubicin would enhance chemotherapeutic response and reduce drug toxicities.

The example of the autophagic pro-survival role in CLL originated from the observation that dasatinib was capable of sustaining stable cellular metabolism from AMPK activation and consequent autophagy motivation, which was also the mechanism of drug resistance (78). However, Morita et al reported that dasatinib induced autophagy-dependent cell death in Bcr-Abl-positive leukemia cells with central nervous system (CNS) infiltration in vitro and in vivo, confirming the important mechanism of autophagy for CNS leukemia treatment (79).

Of note, sorafenib regulated the mTOR or Mcl-1 pathway in multiple myeloma with different outcomes (80): on the one hand, mTOR inhibition by sorafenib induced cytoprotective autophagy; on the other hand, sorafenib-triggered downregulation of Mcl-1 was essential to cell death, and the addition of ABT737 (Bcl-2 antagonist) improved the efficacy of sorafenib. As a result, a combination of sorafenib with autophagy inhibitor and ABT737 is a potentially new treatment strategy in multiple myeloma.

Recently, Takahashi et al demonstrated that L-asparaginase (L-asp)-triggered autophagy contributed to ALL cell survival by eliminating accumulated DNA damage and injured mitochondria with the help of a ROS-p53 loop, indicating that combination treatment with an autophagy inhibitor enhanced anti-leukemic effects of L-asp and overcame drug resistance for ALL patients (81).

Thus, the aforementioned studies fully demonstrated the dual role of autophagy in hematological malignancies, of which induction or inhibition may improve the therapeutic efficacy depending on the types of antitumor agents and pathways of stress responses.

\section{Conclusions and perspectives}

Autophagy, an evolutionarily conserved degradation process, has recently been proven to play a dual role in cancer, by triggering autophagic cell death or by protecting tumor cells from harsh conditions and DNA damage. From the research discussed above in this review, autophagy can be triggered via various conventional chemotherapeutic agents in blood tumors, which results in different effects. Indeed, the outcome of autophagy can be diametrically opposite. Some agent-induced autophagy promotes tumor cell death and prevents disease progression (47-62), whereas in some circumstances, activated autophagy acts as a protective mechanism, and adding autophagy inhibitors enhances treatment efficacy $(72-77,80,81)$. Furthermore, in a few cases, agent-induced autophagy fills both pro-death and pro-survival roles $(66-71,78,79,82,83)$. Thus, therapeutic development in blood tumors targeting autophagy remains to be elucidated. It is well known that, the autophagy signal transduction pathway is intricate, and upregulation or downregulation of autophagy is hampered through diverse molecular regulators at multiple levels. Therefore, the role of autophagy modulated by these drugs depends on cell types, differentiation status, and signal transformation pathways $(84,85)$.

We present different changes of autophagy signaling pathways induced by conventional chemotherapeutic agents and potential combination treatment strategies in Table I, which may improve the therapeutic effect and provide novel targets for the treatment of hematologic malignancies. However, several basic questions remain to be elucidated.

First, induction or inhibition of autophagy is a complicated process because of its dual role in different types of blood tumors with different chemotherapy regimens. Another significant challenge is to determine concrete molecular mechanisms in the process, and interpret the crosstalk between autophagy pathways and intracellular responses. Fully understanding 
these issues may provide more precise treatment involving the addition of autophagy regulators such as mTOR repressor, AMPK agonist, and hydroxychloroquine to increase efficacy and overcome drug resistance. Additionally, some studies did report that autophagy contributed to cell protection and its pharmacological inhibition improved drug sensitivity. Further research is required to determine whether autophagy inhibitors directly affect cell fate or affect it in a more indirect manner.

In the near future, with awareness of the molecular mechanism and accurate targets underlying this complex process, clinicians will identify patients who are likely to benefit from treatment involving autophagy regulation by agonists or blockers.

\section{Acknowledgements}

Not applicable.

\section{Funding}

The present study was supported by the National Natural Science Foundation of China (nos. 81500110, 81370645 and 81670178), the National Key Research and Development Program of China (no. 2016YFC090150X) and the Research Project for Practice Development of National TCM Clinical Research Bases (no. JDZX2015113).

\section{Available data and materials}

All data generated or analyzed during this study are included in this published article.

\section{Author's contributions}

JSH and YLS conceived and designed the study. JSH and WJY researched related literatures and drafted the manuscript. QWB and LH reviewed and revised the manuscript. All authors read and approved the manuscript and agree to be accountable for all aspects of the research in ensuring that the accuracy or integrity of any part of the work are appropriately investigated and resolved.

\section{Ethics approval and consent to participate}

Not applicable.

\section{Consent for publication}

Not applicable.

\section{Competing interests}

The authors declare that they have no conflict of interest.

\section{References}

1. Dong Z, Liang S, Hu J, Jin W, Zhan Q and Zhao K: Autophagy as a target for hematological malignancy therapy. Blood Rev 30 : 369-380, 2016.

2. Helgason GV, Holyoake TL and Ryan KM: Role of autophagy in cancer prevention, development and therapy. Essays Biochem 55: 133-151, 2013
3. Duffy A, Le J, Sausville E and Emadi A: Autophagy modulation: A target for cancer treatment development. Cancer Chemother Pharmacol 75: 439-447, 2015.

4. Klionsky DJ: The molecular machinery of autophagy: Unanswered questions. J Cell Sci 118: 7-18, 2005.

5. Hosokawa N, Hara T, Kaizuka T, Kishi C, Takamura A, Miura Y, Iemura S, Natsume T, Takehana K, Yamada N, et al: Nutrientdependent mTORC1 association with the ULK1-Atg13-FIP200 complex required for autophagy. Mol Biol Cell 20: 1981-1991, 2009.

6. Jung CH, Jun CB, Ro SH, Kim YM, Otto NM, Cao J, Kundu M and Kim DH: ULK-Atg13-FIP200 complexes mediate mTOR signaling to the autophagy machinery. Mol Biol Cell 20: 1992-2003, 2009.

7. Devereaux K, Dall'Armi C, Alcazar-Roman A, Ogasawara Y, Zhou X, Wang F, Yamamoto A, De Camilli P and Di Paolo G: Regulation of mammalian autophagy by class II and III PI 3-kinases through PI3P synthesis. PLoS One 8: e76405, 2013.

8. Petibone DM, Majeed W and Casciano DA: Autophagy function and its relationship to pathology, clinical applications, drug metabolism and toxicity. J Appl Toxicol 37: 23-37, 2017.

9. Hamasaki M, Shibutani ST and Yoshimori T: Up-to-date membrane biogenesis in the autophagosome formation. Curr Opin Cell Biol 25: 455-460, 2013.

10. Fujita N, Itoh T, Omori H, Fukuda M, Noda T and Yoshimori T: The Atg16L complex specifies the site of LC3 lipidation for membrane biogenesis in autophagy. Mol Biol Cell 19: 2092-2100, 2008.

11. Hanada T, Noda NN, Satomi Y, Ichimura Y, Fujioka Y, Takao T, Inagaki $\mathrm{F}$ and Ohsumi Y: The Atg12-Atg5 conjugate has a novel E3-like activity for protein lipidation in autophagy. J Biol Chem 282: 37298-37302, 2007.

12. Geng $\mathbf{J}$ and Klionsky DJ: The Atg8 and Atg12 ubiquitin-like conjugation systems in macroautophagy. 'Protein modifications: Beyond the usual suspects' review series. EMBO Rep 9: 859-864, 2008.

13. Weidberg H, Shvets E, Shpilka T, Shimron F, Shinder V and Elazar Z: LC3 and GATE-16/GABARAP subfamilies are both essential yet act differently in autophagosome biogenesis. EMBO J 29: 1792-1802, 2010.

14. Chua CE, Gan BQ and Tang BL: Involvement of members of the Rab family and related small GTPases in autophagosome formation and maturation. Cell Mol Life Sci 68: 3349-3358, 2011.

15. Liang C, Lee JS, Inn KS, Gack MU, Li Q, Roberts EA, Vergne I, Deretic V, Feng P, Akazawa C, et al: Beclin1-binding UVRAG targets the class $\mathrm{C}$ Vps complex to coordinate autophagosome maturation and endocytic trafficking. Nat Cell Biol 10: 776-787, 2008.

16. Pan H, Chen L, Xu Y, Han W, Lou F, Fei W, Liu S, Jing Z and Sui X: Autophagy-associated immune responses and cancer immunotherapy. Oncotarget 7: 21235-21246, 2016.

17. Stellrecht CM, Vangapandu HV, Le XF, Mao W and Shentu S: ATP directed agent, 8-chloro-adenosine, induces AMP activated protein kinase activity, leading to autophagic cell death in breast cancer cells. J Hematol Oncol 7: 23, 2014.

18. Baehrecke EH: Autophagy: Dual roles in life and death? Nat Rev Mol Cell Biol 6: 505-510, 2005.

19. Gozuacik D and Kimchi A: Autophagy as a cell death and tumor suppressor mechanism. Oncogene 23: 2891-2906, 2004.

20. Bursch W: The autophagosomal-lysosomal compartment in programmed cell death. Cell Death Differ 8: 569-581, 2001.

21. Lin L and Baehrecke EH: Autophagy, cell death, and cancer. Mol Cell Oncol 2: e985913, 2015.

22. Scott RC, Juhász G and Neufeld TP: Direct induction of autophagy by Atg1 inhibits cell growth and induces apoptotic cell death. Curr Biol 17: 1-11, 2007.

23. Yu L, Wan F, Dutta S, Welsh S, Liu Z, Freundt E, Baehrecke EH and Lenardo M: Autophagic programmed cell death by selective catalase degradation. Proc Natl Acad Sci USA 103: 4952-4957, 2006.

24. Nezis IP, Shravage BV, Sagona AP, Lamark T, Bjørkøy G, Johansen T, Rusten TE, Brech A, Baehrecke EH and Stenmark H: Autophagic degradation of dBruce controls DNA fragmentation in nurse cells during late Drosophila melanogaster oogenesis. J Cell Biol 190: 523-531, 2010.

25. Petiot A, Ogier-Denis E, Blommaart EF, Meijer AJ and Codogno P: Distinct classes of phosphatidylinositol 3'-kinases are involved in signaling pathways that control macroautophagy in HT-29 cells. J Biol Chem 275: 992-998, 2000. 
26. Hanada M, Feng J and Hemmings BA: Structure, regulation and function of PKB/AKT - a major therapeutic target. Biochim Biophys Acta 1697: 3-16, 2004.

27. Yu X, Long YC and Shen HM: Differential regulatory functions of three classes of phosphatidylinositol and phosphoinositide 3-kinases in autophagy. Autophagy 11: 1711-1728, 2015.

28. McKnight NC and Zhenyu Y: Beclin 1, an essential component and master regulator of PI3K-III in health and disease. Curr Pathobiol Rep 1: 231-238, 2013.

29. Boya P, González-Polo RA, Casares N, Perfettini JL, Dessen P, Larochette N, Métivier D, Meley D, Souquere S, Yoshimori $\mathrm{T}$, et al: Inhibition of macroautophagy triggers apoptosis. Mol Cell Biol 25: 1025-1040, 2005.

30. Ogata M, Hino S, Saito A, Morikawa K, Kondo S, Kanemoto S, Murakami T, Taniguchi M, Tanii I, Yoshinaga K, et al: Autophagy is activated for cell survival after endoplasmic reticulum stress. Mol Cell Biol 26: 9220-9231, 2006.

31. Moretti L, Yang ES, Kim KW and Lu B: Autophagy signaling in cancer and its potential as novel target to improve anticancer therapy. Drug Resist Updat 10: 135-143, 2007.

32. Ron D: Translational control in the endoplasmic reticulum stress response. J Clin Invest 110: 1383-1388, 2002.

33. Gwinn DM, Shackelford DB, Egan DF, Mihaylova MM, Mery A, Vasquez DS, Turk BE and Shaw RJ: AMPK phosphorylation of raptor mediates a metabolic checkpoint. Mol Cell 30: 214-226, 2008.

34. Schmukler E, Kloog Y and Pinkas-Kramarski R: Ras and autophagy in cancer development and therapy. Oncotarget 5 : 577-586, 2014

35. Downward J: Targeting RAS signalling pathways in cancer therapy. Nat Rev Cancer 3: 11-22, 2003.

36. Byun JY, Yoon CH, An S, Park IC, Kang CM, Kim MJ and Lee SJ: The Rac1/MKK7/JNK pathway signals upregulation of Atg 5 and subsequent autophagic cell death in response to oncogenic Ras. Carcinogenesis 30: 1880-1888, 2009.

37. Pattingre S, Tassa A, Qu X, Garuti R, Liang XH, Mizushima N, Packer M, Schneider MD and Levine B: Bcl-2 antiapoptotic proteins inhibit Beclin 1-dependent autophagy. Cell 122: 927-939, 2005.

38. Levine B, Sinha SC and Kroemer G: Bcl-2 family members: Dual regulators of apoptosis and autophagy. Autophagy 4: 600-606, 2008

39. Inbal B, Bialik S, Sabanay I, Shani G and Kimchi A: DAP kinase and DRP-1 mediate membrane blebbing and the formation of autophagic vesicles during programmed cell death. J Cell Biol 157: 455-468, 2002.

40. Zeng X, Yan T, Schupp JE, Seo Y and Kinsella TJ: DNA mismatch repair initiates 6-thioguanine-induced autophagy through p53 activation in human tumor cells. Clin Cancer Res 13: 1315-1321, 2007.

41. Auberger P and Puissant A: Autophagy, a key mechanism of oncogenesis and resistance in leukemia. Blood 129: 547-552, 2017.

42. Liu T, Zhang Z, Yu C, Zeng C, Xu X, Wu G, Huang Z and Li W: Tetrandrine antagonizes acute megakaryoblastic leukemia growth by forcing autophagy-mediated differentiation. Br J Pharmacol 174: 4308-4328, 2017.

43. Schläfli AM, Isakson P, Garattini E, Simonsen A and Tschan MP: The autophagy scaffold protein ALFY is critical for the granulocytic differentiation of AML cells. Sci Rep 7: 12980, 2017.

44. Pierdominici M, Barbati C, Vomero M, Locatelli SL, Carlo-Stella C, Ortona E and Malorni W: Autophagy as a pathogenic mechanism and drug target in lymphoproliferative disorders. FASEB J 28: 524-535, 2014.

45. Zhang $\mathrm{H}$, Pang $\mathrm{Y}$, Ma C, Li J, Wang $\mathrm{H}$ and Shao Z: ClC5 decreases the sensitivity of multiple myeloma cells to bortezomib via promoting pro-survival autophagy. Oncol Res: Sep 11, 2017 (Epub ahead of print). doi: 10.3727/096504017X1504922123 7147.

46. Yun Z, Zhichao J, Hao Y, Ou J, Ran Y, Wen D and Qun S: Targeting autophagy in multiple myeloma. Leuk Res 59: 97-104, 2017.

47. Mahoney E, Lucas DM, Gupta SV, Wagner AJ, Herman SE, Smith LL, Yeh YY, Andritsos L, Jones JA, Flynn JM, et al: ER stress and autophagy: New discoveries in the mechanism of action and drug resistance of the cyclin-dependent kinase inhibitor flavopiridol. Blood 120: 1262-1273, 2012.
48. Sharma A, Singh K, Mazumder S, Hill BT, Kalaycio M and Almasan A: BECN1 and BIM interactions with MCL-1 determine fludarabine resistance in leukemic B cells. Cell Death Dis 4: e628, 2013.

49. Zakikhani M, Dowling RJ, Sonenberg N and Pollak MN: The effects of adiponectin and metformin on prostate and colon neoplasia involve activation of AMP-activated protein kinase. Cancer Prev Res 1: 369-375, 2008.

50. Wang LW, Li ZS, Zou DW, Jin ZD, Gao J and Xu GM: Metformin induces apoptosis of pancreatic cancer cells. World J Gastroenterol 14: 7192-7198, 2008.

51. Wang F, Liu Z, Zeng J, Zhu H, Li J, Cheng X, Jiang T, Zhang L, Zhang C, Chen T, et al: Metformin synergistically sensitizes FLT3-ITD-positive acute myeloid leukemia to sorafenib by promoting mTOR-mediated apoptosis and autophagy. Leuk Res 39: 1421-1427, 2015

52. Shi WY, Xiao D, Wang L, Dong LH, Yan ZX, Shen ZX, Chen SJ, Chen Y and Zhao WL: Therapeutic metformin/AMPK activation blocked lymphoma cell growth via inhibition of mTOR pathway and induction of autophagy. Cell Death Dis 3: e275, 2012.

53. Xia D, Zhang YT, Xu GP, Yan WW, Pan XR and Tong JH: Sertraline exerts its antitumor functions through both apoptosis and autophagy pathways in acute myeloid leukemia cells. Leuk Lymphoma 58: 1-10, 2017.

54. Trocoli A, Mathieu J, Priault M, Reiffers J, Souquère S, Pierron G, Besançon F and Djavaheri-Mergny M: ATRA-induced upregulation of Beclin 1 prolongs the life span of differentiated acute promyelocytic leukemia cells. Autophagy 7: 1108-1114, 2011.

55. Nishioka C, Ikezoe T, Yang J, Gery S, Koeffler HP and Yokoyama A: Inhibition of mammalian target of rapamycin signaling potentiates the effects of all-trans retinoic acid to induce growth arrest and differentiation of human acute myelogenous leukemia cells. Int J Cancer 125: 1710-1720, 2009.

56. Isakson P, Bjørås M, Bøe SO and Simonsen A: Autophagy contributes to therapy-induced degradation of the PML/RARA oncoprotein. Blood 116: 2324-2331, 2010.

57. Eriksen AB, Torgersen ML, Holm KL, Abrahamsen G, Spurkland A, Moskaug JØ, Simonsen A and Blomhoff HK: Retinoic acid-induced IgG production in TLR-activated human primary B cells involves ULK1-mediated autophagy. Autophagy 11: 460-471, 2015.

58. Qian W, Liu J, Jin J, Ni W and Xu W: Arsenic trioxide induces not only apoptosis but also autophagic cell death in leukemia cell lines via up-regulation of Beclin-1. Leuk Res 31: 329-339, 2007.

59. Goussetis DJ, Altman JK, Glaser H, McNeer JL, Tallman MS and Platanias LC: Autophagy is a critical mechanism for the induction of the antileukemic effects of arsenic trioxide. J Biol Chem 285: 29989-29997, 2010.

60. Ristic B, Bosnjak M, Arsikin K, Mircic A, Suzin-Zivkovic V, Bogdanovic A, Perovic V, Martinovic T, Kravic-Stevovic T, Bumbasirevic V, et al: Idarubicin induces mTOR-dependent cytotoxic autophagy in leukemic cells. Exp Cell Res 326: 90-102, 2014.

61. Grandér D, Kharaziha P, Laane E, Pokrovskaja K and Panaretakis T: Autophagy as the main means of cytotoxicity by glucocorticoids in hematological malignancies. Autophagy 5: 1198-1200, 2009.

62. Laane E, Tamm KP, Buentke E, Ito K, Kharaziha P, Oscarsson J, Corcoran M, Björklund AC, Hultenby K, Lundin J, et al: Cell death induced by dexamethasone in lymphoid leukemia is mediated through initiation of autophagy. Cell Death Differ 16: 1018-1029, 2009

63. Granato M, Chiozzi B, Filardi MR, Lotti LV, Di Renzo L, Faggioni A and Cirone M: Tyrosine kinase inhibitor tyrphostin AG490 triggers both apoptosis and autophagy by reducing HSF1 and Mcl-1 in PEL cells. Cancer Lett 366: 191-197, 2015.

64. Germain M, Nguyen AP, Le Grand JN, Arbour N, Vanderluit JL, Park DS, Opferman JT and Slack RS: MCL-1 is a stress sensor that regulates autophagy in a developmentally regulated manner. EMBO J 30: 395-407, 2011.

65. Granato M, Lacconi V, Peddis M, Lotti LV, Di Renzo L, Gonnella R, Santarelli R, Trivedi P, Frati L, D'Orazi G, et al: HSP70 inhibition by 2-phenylethynesulfonamide induces lysosomal cathepsin D release and immunogenic cell death in primary effusion lymphoma. Cell Death Dis 4: e730, 2013.

66. Crowley LC, Elzinga BM, O'Sullivan GC and McKenna SL: Autophagy induction by Bcr-Abl-expressing cells facilitates their recovery from a targeted or nontargeted treatment. Am J Hematol 86: 38-47, 2011. 
67. Rothe K, Lin H, Lin KB, Leung A, Wang HM, Malekesmaeili M, Brinkman RR, Forrest DL, Gorski SM and Jiang X: The core autophagy protein ATG4B is a potential biomarker and therapeutic target in CML stem/progenitor cells. Blood 123 : 3622-3634, 2014.

68. Mancini M, Leo E, Campi V, Castagnetti F, Zazzeroni L, Gugliotta G, Santucci MA and Martinelli G: A calpain-cleaved fragment of $\beta$-catenin promotes BCRABL1 ${ }^{+}$cell survival evoked by autophagy induction in response to imatinib. Cell Signal 26: $1690-1697,2014$

69. Sheng Z, Ma L, Sun JE, Zhu LJ and Green MR: BCR-ABL suppresses autophagy through ATF5-mediated regulation of mTOR transcription. Blood 118: 2840-2848, 2011.

70. Xin P, Li C, Zheng Y, Peng Q, Xiao H, Huang Y and Zhu X: Efficacy of the dual PI3K and mTOR inhibitor NVP-BEZ235 in combination with imatinib mesylate against chronic myelogenous leukemia cell lines. Drug Des Devel Ther 11: 1115-1126, 2017.

71. Elzinga BM, Nyhan MJ, Crowley LC, O'Donovan TR, Cahill MR and McKenna SL: Induction of autophagy by Imatinib sequesters $\mathrm{Bcr}-\mathrm{Abl}$ in autophagosomes and down-regulates Bcr-Abl protein. Am J Hematol 88: 455-462, 2013.

72. Zhu S, Cao L, Yu Y, Yang L, Yang M, Liu K, Huang J, Kang R, Livesey KM and Tang D: Inhibiting autophagy potentiates the anticancer activity of IFN1@/IFN $\alpha$ in chronic myeloid leukemia cells. Autophagy 9: 317-327, 2013.

73. Bosnjak M, Ristic B, Arsikin K, Mircic A, Suzin-Zivkovic V, Perovic V, Bogdanovic A, Paunovic V, Markovic I, Bumbasirevic V, et al: Inhibition of mTOR-dependent autophagy sensitizes leukemic cells to cytarabine-induced apoptotic death. PLoS One 9: e94374, 2014

74. Pan Y, Gao Y, Chen L, Gao G, Dong H, Yang Y, Dong B and Chen $\mathrm{X}$ : Targeting autophagy augments in vitro and in vivo antimyeloma activity of DNA-damaging chemotherapy. Clin Cancer Res 17: 3248-3258, 2011.

75. Wang Z, Zhu S, Żhang G and Liu S: Inhibition of autophagy enhances the anticancer activity of bortezomib in B-cell acute lymphoblastic leukemia cells. Am J Cancer Res 5: 639-650, 2015.

76. Granato M, Santarelli R, Lotti LV, Di Renzo L, Gonnella R, Garufi A, Trivedi P, Frati L, D'Orazi G, Faggioni A, et al: JNK and macroautophagy activation by bortezomib has a pro-survival effect in primary effusion lymphoma cells. PLoS One 8: e75965, 2013.
77. Han W, Sun J, Feng L, Wang K, Li D, Pan Q, Chen Y, Jin W, Wang X, Pan H, et al: Autophagy inhibition enhances daunorubicin-induced apoptosis in K562 cells. PLoS One 6: e28491, 2011.

78. Martinez Marignac VL, Smith S, Toban N, Bazile M and Aloyz R: Resistance to Dasatinib in primary chronic lymphocytic leukemia lymphocytes involves AMPK-mediated energetic re-programming. Oncotarget 4: 2550-2566, 2013.

79. Morita M, Nishinaka Y, Kato I, Saida S, Hiramatsu H, Kamikubo Y, Heike T, Nakahata T and Adachi S: Dasatinib induces autophagy in mice with Bcr-Abl-positive leukemia. Int J Hematol 105: 335-340, 2017.

80. Kharaziha P, De Raeve H, Fristedt C, Li Q, Gruber A, Johnsson P, Kokaraki G, Panzar M, Laane E, Osterborg A, et al: Sorafenib has potent antitumor activity against multiple myeloma in vitro, ex vivo, and in vivo in the 5T33MM mouse model. Cancer Res 72: 5348-5362, 2012.

81. Takahashi H, Inoue J, Sakaguchi K, Takagi M, Mizutani S and Inazawa J: Autophagy is required for cell survival under L-asparaginase-induced metabolic stress in acute lymphoblastic leukemia cells. Oncogene 36: 4267-4276, 2017.

82. Schnekenburger M, Grandjenette C, Ghelfi J, Karius T, Foliguet B, Dicato M and Diederich M: Sustained exposure to the DNA demethylating agent, 2'-deoxy-5-azacytidine, leads to apoptotic cell death in chronic myeloid leukemia by promoting differentiation, senescence, and autophagy. Biochem Pharmacol 81: 364-378, 2011.

83. Romano A, Giallongo C, La Cava P, Parrinello NL, Chiechi A, Vetro C, Tibullo D, Di Raimondo F, Liotta LA, Espina V, et al: Proteomic analysis reveals autophagy as pro-survival pathway elicited by long-term exposure with 5-azacitidine in high-risk myelodysplasia. Front Pharmacol 8: 204, 2017.

84. Evangelisti C, Evangelisti C, Chiarini F, Lonetti A, Buontempo F, Neri LM, McCubrey JA and Martelli AM: Autophagy in acute leukemias: A double-edged sword with important therapeutic implications. Biochim Biophys Acta 1853: 14-26, 2015.

85. Ekiz HA, Can G and Baran Y: Role of autophagy in the progression and suppression of leukemias. Crit Rev Oncol Hematol 81: 275-285, 2012. 